\title{
Validation of a questionnaire measuring patient satisfaction with general practitioner services
}

\author{
S Grogan, M Conner, P Norman, D Willits, I Porter
}

\begin{abstract}
Background-In order that patient satisfaction may be assessed in a meaningful way, measures that are valid and reliable are required. This study was undertaken to assess the construct validity and internal reliability of the previously developed Patient Satisfaction Questionnaire (PSQ). Method-A total of 1390 patients from five practices in the North of England, the Midlands, and Scotland completed the questionnaire. Responses were checked for construct validity (including confirmatory factor analysis to check the factor structure of the scale) and internal reliability.
\end{abstract}

Results-Confirmatory factor analysis showed that items loaded on the appropriate factors in a five factor model (doctors, nurses, access, appointments, and facilities). Scores on the specific subscales showed highly significant positive correlations with general satisfaction subscale scores suggesting construct validity. Also, the prediction (derived from past research) that older people would be more satisfied with the service was borne out by the results $(F(4,1312)=57.10 ; p<0.0001)$, providing further construct validation. The five specific subscales (doctors, nurses, access, appointments, and facilities), the general satisfaction subscale, and the questionnaire as a whole were found to have high internal reliability (Cronbach's $\alpha=0.74-0.95$ ).

Conclusion-The results suggest that the PSQ is a valid and internally reliable tool for assessing patient satisfaction with general practitioner services.

(Quality in Health Care 2000;9:210-215)

Psychology, University

of Sheffield, Sheffield

S10 2TP

P Norman, senior lecturer

Staithe Surgery, Lower Staithe, Sutton,

Norwich NR12 9BU

D Willits, general

practitioner

Radical Department, North Mersey Community Trust, Mossley Hill Hospital, Liverpool L18 8BU

I Porter, research and development head

Correspondence to: Dr S Grogan

s.grogan@mmu.ac.uk

Accepted 3 October 2000

Assessment of patient satisfaction allows general practitioners to investigate the extent to which their service meets the needs of their client group. ${ }^{1}$ Questionnaires that assess specific aspects of service provision will enable the practitioner to identify aspects of the service where patients are less satisfied, and potentially improve these aspects of care. ${ }^{2}$ Research has shown that satisfied patients are more likely to follow treatment instructions and medical advice, probably because they are more likely to believe that treatment will be effective. ${ }^{3}$ They are also less likely to change doctors and file formal complaints. ${ }^{4}$ It is therefore in the general practitioner's interest to know the extent of patient satisfaction with service provision. ${ }^{5}$

Over the last 10 years there has been increased interest in investigating patient satisfaction with quality of care. Assessing patient satisfaction was a requirement of the 1990 contract for general practitioners in Britain ${ }^{6}$ and more and more practices are surveying patient satisfaction with service provision. ${ }^{78}$ The recent Department of Health publication "Our Healthier Nation" emphasised the importance of obtaining patients' views as a way of improving services. ${ }^{9}$ In order that satisfaction can be assessed in a meaningful way, it is important to develop valid and reliable measures that give practices the information that they need to assess the quality of the process and outcome of care. ${ }^{10}$

Baker ${ }^{11}$ argues that a worthwhile patient satisfaction scale must fulfil three requirements: it must be reliable (produce consistent results), valid (measure what it is designed to test), and show transferability (measure the same constructs when applied to different patient groups). In 1995 we reported the development of a multidimensional scale derived from in depth interviews with patients designed to assess patient satisfaction with all aspects of the general practitioner service. ${ }^{12}$ The scale improved on previous measures of patient satisfaction with general practitioners' services ${ }^{13}$ by incorporating all aspects of care into one questionnaire, rather than assessing satisfaction

Key messages

- It is in the interest of general practitioners to know the extent of patient satisfaction with the service they are providing.

- To assess satisfaction in a meaningful way, valid and reliable measures must be developed that give practices the information needed to asses the quality of the process and outcome of care.

- A worthwhile patient satisfaction scale must be internally reliable, construct valid, and show transferability. 
with the consultation separately from other aspects of the service as had been done by other questionnaires. ${ }^{12}$ It gave a good range of responses in the original sample of patients, avoiding the common pitfall of such measures - that is, the tendency of patients to respond in uniformly positive ways making it difficult to identify the effects of any changes in service provision. ${ }^{14}$ Individual statements were derived from interviews with patients so were phrased in ways that we hoped might make sense to other patients.

The resulting Patient Satisfaction Questionnaire (PSQ) is a 46-item scale with five "specific" subscales to measure satisfaction with doctors (20 items), access (8 items), nurses ( 4 items), appointments ( 4 items), and facilities ( 4 items) plus a separate six-item subscale to measure general satisfaction with the service provided by the practice. We suggested that practices might want to use the questionnaire to assess the adequacy of service provision and to make changes, where appropriate, to meet patient needs more effectively. The full questionnaire is printed in the Appendix. All questions require answers in a strongly agree/strongly disagree Likert scale format. The PSQ remains the only comprehensive patient satisfaction questionnaire that is designed specifically for use in the British general practice context. Other more recent questionnaires are non-UK based and/or designed for hospital patients ${ }^{15-17}$ and recent British measures are designed to look at specific aspects of the service such as care across the primary/ secondary interface. ${ }^{18}$

Initial tests on one sample of patients in Norfolk suggested that the questionnaire was internally reliable and valid. ${ }^{12}$ However, since these patients all came from the same practice, this calls into question the transferability of the scale. We decided to administer the questionnaire to patients from a number of practices to check that the apparent validity and reliability of the scale was not in any way specific to the patients used in the original study. The present study was designed to provide further tests on the PSQ in patients from other practices to address the following objectives:

(1) To test construct validity. We wanted to know whether the questionnaire is construct valid-that is, whether it produces responses that suggest that it is measuring the construct "patient satisfaction" and whether the five specific patient satisfaction dimensions identified in our previous study would be found with a different sample of patients.

(2) To assess internal reliability. We also needed to know whether the questionnaire produces results that are internally consistent - that is, whether items in each subscale seem to be measuring the same dimension.

\section{Methods}

It was decided to use an opportunity sample of participants from a number of practices. Five practices had contacted us between 1997 and 1999 to obtain copies of the PSQ to assess patient satisfaction as part of their internal audit procedures. We asked them to furnish us with the replies for use in the study. We assured them that anonymity would be maintained and that satisfaction data would be reported across practices so that it would not be possible to identify practices where patients were unusually (dis)satisfied with some aspect of the service. Although this led to uneven distributions of responses from different practices, it meant that we ended up with a good geographical spread of responses. The five practices were based in Merseyside, Scotland, and the Midlands. All practices had list sizes of between 5000 and 10000 patients. Two were in rural areas and three in urban areas. Four practices described their patients as "working/middle class" and one as "middle class".

Each practice distributed the questionnaires themselves as part of their normal internal audit procedures and we had no control over exactly how this was done, although we know that practices used reception staff to administer and collect questionnaires when patients attended the practice. Questionnaires had a standard letter attached to the front (written by us) explaining that results would be anonymous and that data would be used as part of an academic validation exercise as well as by the practice for audit. Practices forwarded completed questionnaires to us and we summarised the findings, supplying each practice with a report of satisfaction scores on each subscale.

\section{THE PATIENT SATISFACTION QUESTIONNAIRE}

(PSQ)

This comprised 46 patient satisfaction items and demographic information (see Appendix). Participants ticked the box (from "strongly agree" to "strongly disagree") that corresponded most closely to their response to each statement. Responses were coded 1-5 from "strongly agree" to "strongly disagree". Negatively worded questions were reverse scored (so that $1=5$, etc) so that in all cases a low score indicated satisfaction.

\section{ANALYSIS}

Items relating to each of the subscales were first combined to produce means and standard deviations for each subscale. We looked at the distribution of scores to check that patients were using the full range of possible scoresthat is, that they were not giving uniformly satisfied or dissatisfied responses. We also checked that scores did not show evidence of skewness - that is, that the distribution of scores was roughly symmetrical about the mean-or kurtosis - that is, that the distributions were not too peaked or too flat.

To test construct validity we checked:

(1) that the five factors identified in the original study would be found with this sample of patients when data were analysed using confirmatory factor analysis. We expected that data would factor out into the same five dimensions (doctors, nurses, access, appointments, facilities) that we had identified in the original study if this factor 
structure was a valid representation of the construct "patient satisfaction";

(2) that scores on each specific subscale correlated significantly with scores on the general satisfaction subscale (using Pearson's product moment correlation test). If subscales measured related constructs then we expected that each would correlate significantly with "general satisfaction" scores;

(3) that the scale differentiated between different subgroups within the population (using analysis of variance). One of the most consistent findings in the patient satisfaction literature is that older people report more satisfaction with health care provision than younger people. ${ }^{314} \mathrm{We}$ therefore predicted that our scale should find age differences in satisfaction if it is construct valid.

We checked the internal consistency (reliability) of the scale by investigating whether items within each subscale correlated significantly with each other (using Cronbach's $\alpha$ statistic). We expected that each subscale would produce values of $\alpha$ of 0.7 or above, indicating internal reliability.

\section{Results}

We received 51, 73, 129, 203, and 967 responses from the five practices; 33 questionnaires $(2.3 \%)$ were spoiled and were eliminated, leaving 1390 completed questionnaires for analysis. We did not have response rates for all practices because not all kept records of numbers of questionnaires distributed. However, of those that did keep such records, response rates ranged from $48 \%(n=129)$ to $68 \%(n=967)$. Of those patients who reported demographic information, $876(63 \%)$ were women and 504 (37\%) were men; 198 (15\%) were aged under $30,244(19 \%)$ were aged 30-39, $234(18 \%)$ 40-49, 226 (17\%) 50-59, and $415(31 \%)$ were over 60 years. Ten people $(0.7 \%)$ did not specify their sex and $73(5.3 \%)$ did not give their age.

The results are presented across the sample (rather than practice by practice) to retain confidentiality and anonymity, and because this is intended to be a test of construct validity and internal reliability of the questionnaire rather than a comparison between different practices.

When we checked the distribution of the data we found that responses on all subscales were normally distributed and the full range of responses on each scale (from 1 to 5) was found. Means and standard deviations (SD) on each subscale are given in table 1. In general, there was greater variation in satisfaction with appointments than with any of the other aspects of the service.

\section{CONSTRUCT VALIDITY}

Confirmatory factor analysis

Confirmatory factor analysis (CFA) ${ }^{19}$ was carried out to see how closely the data from the 40 specific items fitted the five factor model proposed by Grogan et $a l^{12}$ in 1995-that is, the extent to which items loaded on the appropri-
Table 1 Mean (SD) values for each subscale $(n=1390)$

\begin{tabular}{ll}
\hline Subscale & Mean (SD) \\
\hline Doctors & $2.26(0.64)$ \\
Nurses & $2.40(0.65)$ \\
Access & $2.59(0.66)$ \\
Appointments & $2.82(1.04)$ \\
Facilities & $2.19(0.68)$ \\
\hline
\end{tabular}

Table 2 Model fit indices $(n=1318)$

\begin{tabular}{llll}
\hline Model & $\chi^{2}$ value & $\chi^{2}$ ratio & NNFI \\
\hline Null model & 16127 & 84.9 & 0.01 \\
One factor model & 5315 & 31.3 & 0.64 \\
Five factor model & 1019 & 6.4 & 0.94 \\
\hline
\end{tabular}

$\mathrm{NNFI}=$ non-normed fit index.

ate factors. Analysis was only carried out for participants where full data sets were available $(\mathrm{n}=1151)$. CFA tests whether a proposed model "fits" the observed variance covariation matrix between items. The five factor model (which loads blocks of items onto those factors found in the study by Grogan et $a l^{12}$ ) was tested against a null model which assumes zero covariance between items - that is, no factors - and a one factor model that assumes that all items load on a single factor-that is, that all items measure a unitary concept of "satisfaction". The "fit" of these models was tested in several ways. The $\chi^{2}$ statistic gives an indication of overall fit to the model (a large value of $\chi^{2}$ indicates a poor fit and a ratio of $\chi^{2}$ to the number of parameters of less than 10 indicates an acceptable fit). The non-normed fit index (NNFI) was also calculated and provides a measure of the fit of each model which is not influenced by sample size, unlike the $\chi^{2}$ measure. The NNFI indicates the proportion of variance explained relative to the null model, so an NNFI value of greater than 0.9 represents a very good fit. Good model fits with CFA are not usually possible when there are more than four indicators (items) per factor. ${ }^{19}$ "This presented difficulties in relation to the "doctors" and "access" subscales (which have 20 and 8 items, respectively). Therefore, for these two subscales we averaged items to give four indicators per factor-that is, a random selection of four groups of five items for the "doctors" scale and four pairs of items for the "access" scale, as suggested by Bagozzi and Edwards. ${ }^{20}$

Data revealed that the null model and one factor model were poor fits to the data. However, the hypothesised five factor model gave a good fit with a low $\chi^{2}$ ratio and an NNFI in excess of 0.9 (table 2). This indicates that each of the items on the scale loaded significantly on the appropriate factor-that is, that all the "doctor" items loaded significantly on the "doctor" factor.

Correlation of subscale scores with general satisfaction scores

To test the construct validity of the specific subscales as measures of patient satisfaction, scores were first correlated with general satisfaction subscale scores. Scores on the general satisfaction subscale showed a significant positive correlation with scores on all the 
Table 3 Correlation between subscales and general satisfaction scores $(r)$ and $\beta$ weights from multiple regression analysis $(n=1390)$

\begin{tabular}{lllll}
\hline Subscale & $r$ & $p$ value & $\beta$ & $p$ value \\
\hline Doctors & 0.83 & $<0.001$ & 0.67 & $<0.001$ \\
Nurses & 0.51 & $<0.001$ & 0.07 & $<0.001$ \\
Access & 0.62 & $<0.001$ & 0.04 & NS \\
Appointments & 0.54 & $<0.001$ & 0.10 & $<0.001$ \\
Facilities & 0.41 & $<0.001$ & 0.13 & $<0.001$ \\
\hline
\end{tabular}

Table 4 Reliability coefficients for each subscale $(n=$ 1390)

\begin{tabular}{lll}
\hline & No. of items & $a$ \\
\hline Doctors & 20 & 0.95 \\
Nurses & 4 & 0.74 \\
Access & 8 & 0.86 \\
Appointments & 4 & 0.88 \\
Facilities & 4 & 0.74 \\
General satisfaction & 6 & 0.80 \\
\hline
\end{tabular}

specific subscales, suggesting that all subscales were measuring some aspect of patient satisfaction. Multiple regression analysis revealed that $72 \%$ of variance in general satisfaction subscale scores was explained by scores on the five specific subscales $(\mathrm{F}(5,1384)=707.37$; $\mathrm{p}<0.0001)$. Beta weights revealed that all subscales except for "access" made a significant individual contribution to explaining variance in general satisfaction subscale scores, with the "doctor" subscale showing the strongest predictive power (table 3).

\section{Discrimination between scores of participants of different ages}

In order to further check the construct validity of the scale, we divided participants into five age groups and compared total satisfaction scores on the whole 46-item questionnaire using ANOVA. As predicted, there were significant differences in satisfaction scores in the expected direction, with older participants significantly more likely to be satisfied with service provision $(\mathrm{F}(4,1312)=57.10$; $\mathrm{p}<0.0001)$. Mean (SD) scores were as follows: under 30 years $=2.65(0.50) ; 30-39$ years $=$ $2.53(0.63) ; 40-49$ years $=2.42(0.57) ; 50-59$ years $=2.33(0.52)$; over 60 years $=2.06$ $(0.47)$.

\section{INTERNAL RELIABILITY}

This was assessed by performing Cronbach's $\alpha$ on each specific subscale and on the general satisfaction subscale. All subscales were internally reliable with $\alpha$ coefficients ranging from 0.74 to 0.95 (table 4 ).

\section{Discussion}

The main aims of this study were to check the construct validity and internal reliability of the PSQ derived by Grogan et al. ${ }^{12}$ We found that the scale was internally reliable and construct valid when tested on a sample of patients from a number of different practices. These results show that the questionnaire satisfies the criteria of Baker $^{11}$ for an adequate scale: it has construct validity, is internally reliable, and appears to measure the same constructs when applied to a new group of patients (which Baker terms "transferability").
On construct validity the scale performed as predicted. The five factor structure of the scale-where subscales specifically measure satisfaction with doctors, nurses, access, appointments, and facilities-was also confirmed. These five dimensions seem to be at the core of satisfaction with the service. Scores on each subscale correlated significantly with "general satisfaction", suggesting that each subscale measures some aspect of patient satisfaction. Scores on the questionnaire also differentiated between patients of different ages as predicted by previous research. ${ }^{314}$ Satisfaction with the service provided by general practitioners themselves was important in predicting satisfaction with the service as a whole (table 2). Clearly, doctor's perceived communication skills, clinical competence, and perceived time pressure have a significant impact on patient satisfaction with the service, as suggested by other researchers. ${ }^{13}$

Analysis also revealed that each of the subscales was internally reliable - that is, that items asked related questions - and that scores on each subscale were related to "general satisfaction" as scored on the six-item subscale, which suggests that they were all asking questions that impacted on patients' general satisfaction with the practice. The "doctor" subscale emerged yet again as a unitary construct, with all items loading highly on this dimension, which suggests (as in the previous study by Grogan et $a l^{12}$ ) that patients do not differentiate between different aspects of the consultation (such as information giving, information getting, clinical competence) in terms of satisfaction. This conflicts with suggestions that satisfaction with the service provided by the doctor factors into different components such as communication skills and clinical competence ${ }^{13}$ and supports the proposal by Kenny ${ }^{21}$ that doctors' skills cannot be easily dichotomised into "affective" and "technical" dimensions. Satisfaction with the appointments system also factored out as a separate scale, suggesting that patients differentiate between more general "access" issues and satisfaction with the appointments system. This also validated our previous suggestion ${ }^{12}$ that practices could remove this subscale from the questionnaire if they do not have an appointments system without affecting the validity of the rest of the questionnaire.

We have reproduced the full questionnaire in the Appendix, with indications of the subscale from which each item comes. The questionnaire can be used to look at specific areas of provision and/or at the service as a whole. If changes have been made in a particular area, particular subscales can be used to assess the effects of the change. We suggest that practices also incorporate a "free response space" at the end of the questionnaire to pick up idiosyncratic aspects of the service perceived as satisfactory or unsatisfactory by patients. Qualitative analysis of such statements adds significantly to evaluation of the service. ${ }^{1}$ The questionnaire can be given to patients as they arrive at the surgery, or sent to them at home if a broader sample of responses is required. It 
can also be directed to particular patient groups such as parents of children under 16, people who have used the out of hours services, people over 60 by reference to patient records if a practice needs to know about appropriateness of service for a particular patient group.

The present findings support the reliability and validity of the PSQ when used with an independent sample of patients. The scale can be a useful tool for assessing patient satisfaction with service provision to help general practices determine how well they are meeting the needs of their patients. Further research could check other aspects of reliability and validity of the questionnaire. For instance, it would be informative to check the test-retest reliability of the scale over a short time lag to check that results are consistent over time. Similarly, checks of the criterion related validity of the scale (tested against patient transfers out of the practice, for instance) would be interesting. Clearly there is work that could be done to understand fully the uses and limitations of the questionnaire, but we are confident that it will be useful to practitioners in its present form.

1 Avis $\mathrm{M}$, Bond M, Arthur A. Satisfying solutions? A review of some unresolved issues in the measurement of patient satisfaction. F Advan Nurs 1995;22:316-22.

2 Harris LE, Swindle RW, Mungai SM, et al. Measuring patient satisfaction for quality improvement. Med Care patient satisfaction

3 Hardy GE, West MA, Hill F. Components and predictors of patient satisfaction. Br F Health Psychol 1996;1:65-85.

4 Taylor SE Health psychology. New York: McGraw Hill, 1995.

5 Woodward CA, Ostbye T, Craighead J, et al. Patien satisfaction as an indicator of quality care in independent health facilities: developing and assessing a tool to enhance public accountability. Am f Med Qual 2000;15:94-105.
6 Department of Health and the Welsh Office. General practice in the National Health Service: a new contract. London: HMSO, 1989.

7 Baker R, Streatfield J. What type of practice to patients prefer? Exploration of practice characteristics influencing patient satisfaction. Br f Gen Pract 1995;45:654-9.

8 Kinnersley P, Anderson E, Parry K, et al. Randomised controlled trial of nurse practitioner versus general practitioner care for patients requesting 'same day' consultations in primary care. BMF 2000;320:1043-8.

9 Department of Health. Our healthier nation: a contract for health. London: HMSO, 1998.

10 Trout A, Magnusson AR, Hedges JR. Patient satisfaction investigations and the emergency department: what does the literature say? Acad Emerg Med 2000;7:675-709.

11 Baker R. The reliability and criterion validity of a measure of patients' satisfaction with their general practice. Family Pract 1991;8:171-7.

12 Grogan S, Conner M, Willits D, et al. Development of a questionnaire to measure patients' satisfaction with general practitioners' services. Br F Gen Pract 1995;45:525-9.

13 Baker R. Development of a questionnaire to assess patients' satisfaction with consultations in general practice. $\mathrm{Br} \mathcal{F} \mathrm{Gen}$ Pract 1990;40:487-90.

14 Sitzia J, Wood N. Patient satisfaction: a review of issues and concepts. Soc Sci Med 1997;45:1829-43.

15 Arpinelli F, Visona G, Recchia G. A new questionnaire to measure patient satisfaction with general practice: the Verona patient satisfaction questionnaire VPSQ. Quality of Life Res 1997;6:7-8.

16 Loblaw DA, Bezjak A, Bunston T. Development and testing of a visit-specific patient satisfaction questionnaire: The Princess Margaret Hospital Satisfaction with Doctor QuesPrincess Margaret Hospital Satisfaction

17 Paddock LE, Veloski J, Chatterton ML, et al. Development and validation of a questionnaire to evaluate patient satisfaction with diabetes disease management. Diabetes Care 2000;23:951-6.

18 Baker R, Preston C, Cheater F, et al. Measuring patients' attitudes to care across the primary/secondary interface: the development of the patient career diary. Quality in Health Care 1999;8:154-60.

19 Joreskog KG, Sorbom D. LISREL 7: a guide to the program and applications. Chicago: SPSS, 1988

20 Bagozzi RP, Edwards JR. A general approach for representing constructs in organizational research. Org Res Meth 1998;1:45-87.

21 Kenny DT. Determinants of patient satisfaction with the medical consultation. Psychol Health 1995;10:427-37. 
Appendix: The Patient Satisfaction Questionnaire (subscales for each item indicated in parentheses)

Please indicate your degree of agreement with the following statements by placing a tick in the appropriate box. There are no right or wrong answers-we are simply interested in your views

\begin{tabular}{|c|c|c|c|c|c|}
\hline & Strongly agree & Agree & $\begin{array}{l}\text { Neither agree } \\
\text { nor disagree }\end{array}$ & Disagree & $\begin{array}{l}\text { Strongly } \\
\text { disagree }\end{array}$ \\
\hline $\begin{array}{l}\text { 1. Patients receive the best care from the staff working at this practice } \\
\text { (General satisfaction) }\end{array}$ & $\square$ & $\square$ & $\square$ & $\square$ & $\square$ \\
\hline 2. I feel it is easy to speak to my doctor by telephone (Access) & $\square$ & $\square$ & $\square$ & $\square$ & $\square$ \\
\hline $\begin{array}{l}\text { 3. The doctor clearly explains what is wrong before giving any treatment } \\
\text { (Doctors) }\end{array}$ & $\square$ & $\square$ & $\square$ & $\square$ & $\square$ \\
\hline 4. Getting an appointment at a convenient time is easy (Appointments) & $\square$ & $\square$ & $\square$ & $\square$ & $\square$ \\
\hline $\begin{array}{l}\text { 5. The practice nurses do not take care to explain things carefully } \\
\text { (Nurses) }\end{array}$ & $\square$ & $\square$ & $\square$ & $\square$ & $\square$ \\
\hline 6. The doctor does enough tests to find out what is wrong (Doctors) & $\square$ & $\square$ & $\square$ & $\square$ & $\square$ \\
\hline $\begin{array}{l}\text { 7. I have absolute faith and confidence in the doctors (General } \\
\text { satisfaction) }\end{array}$ & $\square$ & $\square$ & $\square$ & $\square$ & $\square$ \\
\hline $\begin{array}{l}\text { 8. The doctor is always available to give advice over the telephone } \\
\text { (Access) }\end{array}$ & $\square$ & $\square$ & $\square$ & $\square$ & $\square$ \\
\hline 9. The doctor does not tell me enough about the treatment (Doctors) & $\square$ & $\square$ & $\square$ & $\square$ & $\square$ \\
\hline 10. The surgery building could do with some improvements (Facilities) & $\square$ & $\square$ & $\square$ & $\square$ & $\square$ \\
\hline $\begin{array}{l}\text { 11. The doctor fully explains how the illness will affect my future health } \\
\text { (Doctors) }\end{array}$ & $\square$ & $\square$ & $\square$ & $\square$ & $\square$ \\
\hline 12. It is easy to get advice over the telephone (Access) & $\square$ & $\square$ & $\square$ & 口 & $\square$ \\
\hline $\begin{array}{l}\text { 13. The doctor is very careful to check everything when examining me } \\
\text { (Doctors) }\end{array}$ & $\square$ & $\square$ & $\square$ & $\square$ & $\square$ \\
\hline 14. I am satisfied with the out of hours service (Access) & $\square$ & $\square$ & $\square$ & $\square$ & $\square$ \\
\hline 15. The doctor is always interested (Doctors) & $\square$ & $\square$ & $\square$ & $\square$ & $\square$ \\
\hline $\begin{array}{l}\text { 16. The practice has good facilities for dealing with emergencies which } \\
\text { occur when the surgery is closed (Access) }\end{array}$ & $\square$ & $\square$ & $\square$ & $\square$ & $\square$ \\
\hline $\begin{array}{l}\text { 17. The doctor always asks about how my illness affects everyday life } \\
\text { (Doctors) }\end{array}$ & $\square$ & $\square$ & $\square$ & $\square$ & $\square$ \\
\hline $\begin{array}{l}\text { 18. I sometimes feel I have not been given enough information by the } \\
\text { doctor (Doctors) }\end{array}$ & $\square$ & $\square$ & $\square$ & $\square$ & $\square$ \\
\hline 19. I am not satisfied with my doctor (General satisfaction) & $\square$ & $\square$ & $\square$ & $\square$ & $\square$ \\
\hline $\begin{array}{l}\text { 20. The practice nurse does not always listen carefully when I talk about } \\
\text { my problems (Nurses) }\end{array}$ & $\square$ & $\square$ & $\square$ & $\square$ & $\square$ \\
\hline $\begin{array}{l}\text { 21. There are one or two things about this surgery I am not happy about } \\
\text { (General satisfaction) }\end{array}$ & $\square$ & $\square$ & $\square$ & $\square$ & $\square$ \\
\hline 22. The waiting room is uncomfortable (Facilities) & $\square$ & $\square$ & $\square$ & $\square$ & $\square$ \\
\hline 23. The receptionists explain things clearly to me (Access) & $\square$ & $\square$ & $\square$ & $\square$ & $\square$ \\
\hline $\begin{array}{l}\text { 24. Sometimes the doctor makes me feel I am wasting his/her time } \\
\text { (Doctors) }\end{array}$ & $\square$ & $\square$ & $\square$ & 口 & $\square$ \\
\hline $\begin{array}{l}\text { 25. I don't feel confident discussing my problems with the doctor } \\
\text { (Doctors) }\end{array}$ & $\square$ & $\square$ & $\square$ & $\square$ & $\square$ \\
\hline $\begin{array}{l}\text { 26. Appointments are easy to make whenever I need them } \\
\text { (Appointments) }\end{array}$ & $\square$ & $\square$ & $\square$ & $\square$ & $\square$ \\
\hline $\begin{array}{l}\text { 27. The doctor seems to want to get rid of me as soon as possible } \\
\text { (Doctors) }\end{array}$ & $\square$ & $\square$ & $\square$ & $\square$ & $\square$ \\
\hline $\begin{array}{l}\text { 28. The doctor gives me every chance to talk about all my problems } \\
\text { (Doctors) }\end{array}$ & $\square$ & $\square$ & $\square$ & $\square$ & $\square$ \\
\hline $\begin{array}{l}\text { 29. I feel perfectly satisfied with the way I am treated at the surgery } \\
\text { (General satisfaction) }\end{array}$ & $\square$ & $\square$ & $\square$ & $\square$ & $\square$ \\
\hline $\begin{array}{l}\text { 30. It is often difficult to get an appointment with a doctor } \\
\text { (Appointments) }\end{array}$ & $\square$ & $\square$ & $\square$ & $\square$ & $\square$ \\
\hline 31. The doctor sometimes fails to appreciate how ill I am (Doctors) & $\square$ & $\square$ & $\square$ & $\square$ & $\square$ \\
\hline 32. The doctor shows a genuine interest in my problems (Doctors) & $\square$ & $\square$ & $\square$ & $\square$ & $\square$ \\
\hline 33. The receptionists ask patients the right questions (Access) & $\square$ & $\square$ & $\square$ & $\square$ & $\square$ \\
\hline 34. There are not enough seats in the waiting room (Facilities) & $\square$ & $\square$ & $\square$ & $\square$ & $\square$ \\
\hline 35. The doctor does everything needed to arrive at a diagnosis (Doctors) & $\square$ & $\square$ & $\square$ & $\square$ & $\square$ \\
\hline 36. The practice nurse is always very reassuring. (Nurses) & $\square$ & $\square$ & $\square$ & $\square$ & $\square$ \\
\hline 37. The doctor always puts me at ease (Doctors) & $\square$ & $\square$ & $\square$ & $\square$ & $\square$ \\
\hline 38. The waiting room seats are uncomfortable (Facilities) & $\square$ & $\square$ & $\square$ & $\square$ & $\square$ \\
\hline 39. It is easy to see the doctor of my choice (Appointments) & $\square$ & $\square$ & $\square$ & $\square$ & $\square$ \\
\hline 40. The doctor is very understanding (Doctors) & $\square$ & $\square$ & $\square$ & $\square$ & $\square$ \\
\hline 41. I have thought of changing to another practice (General satisfaction) & $\square$ & $\square$ & $\square$ & $\square$ & $\square$ \\
\hline 42. Even when the doctor is busy I am examined properly (Doctors) & $\square$ & $\square$ & $\square$ & $\square$ & $\square$ \\
\hline 43. I can speak to a receptionist privately if I wish (Access) & $\square$ & $\square$ & $\square$ & $\square$ & 口 \\
\hline 44. The doctor knows when tests are necessary (Doctors) & $\square$ & $\square$ & 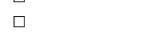 & $\square$ & $\square$ \\
\hline $\begin{array}{l}\text { 45. The practice nurse makes me feel that I'm wasting his/her time } \\
\text { (Nurse) }\end{array}$ & $\square$ & $\square$ & $\square$ & $\square$ & $\square$ \\
\hline 46. I do not feel rushed when I am with the doctor (Doctors) & $\square$ & $\square$ & $\square$ & $\square$ & $\square$ \\
\hline
\end{tabular}

46. I do not feel rushed when I am with the doctor (Doctors)

Finally, we would ask you a few questions about yourself so that we can see how different groups of people (e.g. men/women) feel about the services offered by their General Practice.

1. Are you:

2. Are you disabled?

3. How old are you?

. How old are you?

5. How many times have you seen the doctor in the last year?

6 . How many times has the doctor come to see you at home in the past year?

7. How many times have you tried to contact the doctor when the surgery was closed in the past year 